\title{
Numerical and Experimental Analysis of Total Hull Resistance on Floating Catamaran Pontoon for N219 Seaplanes based on Biomimetics Design with Clearance Configuration
}

\author{
Yanuar $^{1 *}$, Gunawan ${ }^{1}$, Allessandro Setyo Anggito Utomo ${ }^{1}$, Muhammad Naufal Luthfi ${ }^{1}$, \\ Muthia Aurora Balqis Baezal ${ }^{1}$, Fadlu Rahman Sirajudin Majid ${ }^{1}$, Zahwa Chairunisa ${ }^{1}$ \\ ${ }^{1}$ Department of Mechanical Engineering, Faculty of Engineering, Universitas Indonesia, Kampus UI Depok, \\ Depok 16424, Indonesia
}

\begin{abstract}
Seaplanes are planes that can take off and land from the surface of water. Due to their ability to take off and land from the surface of water, seaplanes need a pair of pontoons in the form of a catamaran hull at the bottom of seaplanes so that the seaplanes can float above the surface of water. Research on the catamaran hull model was conducted to examine the effect of istiophorus platypterus design distance between hulls (clearance) variation on the total resistance of the catamaran hull model through experimental method and computational fluid dynamics (CFD) simulation method. There are three values of clearance (S/L) used in this research: $0.15,0.2$, and 0.25 . The most optimal clearance configuration can be determined using a configuration which has the lowest total resistance. The results of experiments and simulations show that the distance between hull variations has a considerable effect on the total resistance of the catamaran hull model. The catamaran hull, which has the optimal clearance configuration, will cause the resulting wave interference and resistance to be small. The model was towed with Froude numbers ranging from 0.35 to 0.65 . The results showed that hull separation made a difference in the total resistance coefficient on the same experiment configurations. The configurations with S/L 0.25 showed the least total resistance coefficient, whereas the configurations with the S/L 0.15 showed the highest total resistance coefficient. The simulations were conducted with the model with Froude numbers ranging from 0.35 to 0.65 using 700,000 cells in meshing and an error rate of $7.6 \%$ in convergence.
\end{abstract}

Keywords: Catamaran; Computational fluid dynamics; Clearance; Resistance; Seaplanes

\section{Introduction}

Float on seaplanes has a catamaran-type hull. There have been many studies that have attempted to create an optimal catamaran hull. Yang et al. (2002) examined the optimization of wave cancellations in multihull using computational fluid dynamics (CFD) tools. Efforts to reduce wave resistance in the sub-district were also investigated by Danıșman (2014) using the center bulb optimization concept Motion Sickness Incidence (MSI) in catamarans was also reviewed by Piscopo and Scamardella (2015). Research related to catamaran hulls will continue to grow, considering that $40 \%$ of ships worldwide use this type of hull design (Papanikolaou, 2005; Samuel et al., 2015).

Design optimization on a float can be seen from the total resistance, that will be

${ }^{*}$ Corresponding author's email: yanuar@eng.ui.ac.id, Tel.: +62-813-8578-4345 doi: 10.14716/ijtech.v11i7.4503 
described as follows. The total resistance is composed of viscous resistance related to the Reynolds number and wave resistance, which depends on the Froude number (Yanuar and Ibaddurahman, 2019). In the context of seaplane float, the optimization of catamaran designs is assessed based on the characteristics of the catamaran while in water, namely: (1) static load on water in the form of the width of each hull and total load on the floatplane; (2) float geometry; (3) position of the step float relative to the CG point (center of gravity) on the floatplane; (4) wing adjustment to the floatplane; (5) aerodynamic characteristics; and (6) the distance between the float centers. Good consideration of the characteristics of the float produces a design with stability in water, trim, spray, seaworthiness in the waves, aerodynamic shape, buoyancy, and ease in optimal manufacturing (Tomaszewski, 1950).

One of the optimization efforts that is often done in design engineering is biomimicry. This type of engineering is a process to create sustainable designs by mimicking the shape, mechanism, or evolution of various animals to the ecosystem they occupy (Pohlmann, 2016). In marine ecosystems, for example, the evolution of marine animals that have lasted more than 600 million years is believed to be the best and most efficient way of survival for these animals (Sani et al., 2013). With a variety of marine waters, these animals are able to survive, adapt to their environment, evolve, and survive extinction (Fish and Kocak, 2011). Sailfish (Istiophorus platypterus) is known as one of the fish that can go at high speed in the depths of the sea with an average speed of up to $30 \mathrm{~km} / \mathrm{h}$. Supported by body dimensions that can reduce barriers significantly, the swimming speed of the sailfish a type of fish is estimated to reach up to $126 \mathrm{~km} / \mathrm{h}$, one of the fastest when compared to other fish species (Svendsen et al., 2016). The aim and objective of this research are to create an optimal catamaran hull design which can be applied as a float on N219 aircraft by adapting the hydrodynamic characteristics of sailfish.

Float on seaplanes has a catamaran-type hull shape. Design optimization on a float can be seen from the total resistance. Sailfish (Istiophorus platypterus) have body dimensions that can significantly reduce barriers. The aim and objective of this research are to create a catamaran hull design as a float on N219 aircraft by adapting the hydrodynamic characteristics of sailfish. Tests using numerical methods are performed to determine the flow visualization of new hull designs' hydrodynamic characteristics. The adaptation of the hydrodynamic characteristics of sailfish on catamaran hulls is expected to optimize aircraft float design.

One mode of transportation that is currently being made in Indonesia is seaplanes. Seaplanes are specialized aircraft that can operate off the water and, thus, are completely independent of regular land-based airfields (Gudmundsson, 2013). Due to this ability, seaplanes can be operated to remote areas or islands in Indonesia as long as they have a large enough water surface area. Seaplanes can in general use wheels like planes for takeoff and landing on land and use pontoons to take off and land on the surface of water. The National Aeronautics and Space Agency and PT Dirgantara Indonesia are working together to develop a type of N219 aircraft that can be operated from land and the surface of water. The first stage in the development of amphibious N219 aircraft is the development of pontoons of the aircraft so that the aircraft can take off and land on the surface of water. The pontoons used in this N219 seaplane manuscript are in the form of a catamaran hull.

The application of catamaran hulls in the mode of transportation has developed rapidly today and is likely to continue to develop in the future (Moraes et al., 2007; Iqbal and Samuel, 2017; Yanuar et al., 2019). The rapid development of catamaran hulls as a mode of transportation is due to the catamaran hull dock area and the safety of its stability (Seif and Amini, 2004; Zouridakis, 2005). 
Multihull ships, including catamarans, have technical challenges, such as wave interference with various configurations when operated at high speeds, as stated by Yanuar et al. (2013). Catamaran hulls can have a small drag force by adjusting the proper hull distance ratio to create better efficiency. On multihull vessels, including catamarans, the problem of resistance is still widely discussed. Several studies on hull distance ratio have been investigated (Insel and Molland, 1992) as well as several experiments on catamaran resistance (Everest, 1968; Pien, 1976; Oving, 1985). This research aims to find the hull separation ratio (clearance) on a catamaran hull model for an N219 seaplane based on biomimetics to optimize the design using an experimental method and CFD simulation.

\section{Methods}

There are two methods used in this research: the experimental method and the CFD method. In the experimental method, the researchers began by deciding the clearance configuration that will be used on the model. Next, the researchers created the model, and then the researchers made variations of the model based on the clearance configuration that had been decided. After making variations of the model, the researchers used an experimental method to calculate the catamaran model resistance. The model with the lowest resistance was considered the best. In the CFD method, the researchers began by creating the 3D model based on the real model. Then, the researchers made variations of the 3D model based on the clearance configuration that had been decided. After making variations of the 3D model, the researchers used CFD simulation to calculate the 3D model resistance. The 3D model with the lowest resistance was considered the best.

\subsection{Experimental Method}

Both main hulls in this research have the same dimension. The hulls were arranged like a catamaran configuration where one of the hulls was longitudinally aligned with its pair. Table 1 shows the main dimensions of the catamaran model; also, Figure 1 shows the lines plan of the catamaran model.

Table 1 Main dimension of the catamaran model

\begin{tabular}{lcc}
\hline \multicolumn{1}{c}{ Parameter } & Symbol & Main Hull \\
\hline Length $(\mathrm{m})$ & $L O A$ & 1.255 \\
Beam $(\mathrm{m})$ & $B$ & 0.110 \\
Height $(\mathrm{m})$ & $H$ & 0.107 \\
Draft $(\mathrm{m})$ & $T$ & 0.042 \\
Block coefficient & $C b$ & 0.530 \\
Wetted surface area $\left(\mathrm{m}^{2}\right)$ & $S a$ & 0.270 \\
\hline
\end{tabular}

The experiment was tested in calm water conditions. The catamaran model was tested at seven variations of hull distance ratio in Froude number ranging from 0.35 to 0.65 . The pool where the experiment took place was $50 \mathrm{~m}$ long, 25 wide, and $5 \mathrm{~m}$ deep, using ITTC (2011) recommendation to follow through the experimental procedure. The equipment used in this experiment consisted of a load cell that had been calibrated from the previous usage, a data acquisition set, a laptop, and a towing tool. Load cells were used to measure the total resistance of the catamaran model. Data acquisition was used to transmit data from the load cell to the laptop. A computer was used to display data that had been measured by a load cell. The towing tool consisted of rope, rope reel, electric motor, and voltage regulator. Figure 2 shows the schematic drawing of the experimental setup and basic geometry definition of the catamaran model. 


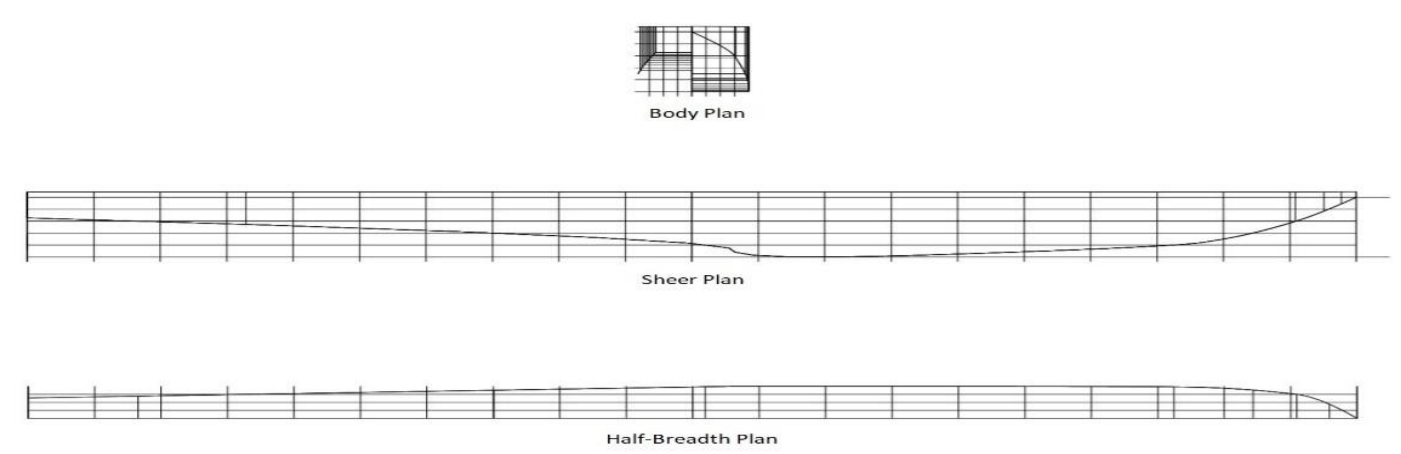

Figure 1 Lines plan of catamaran model

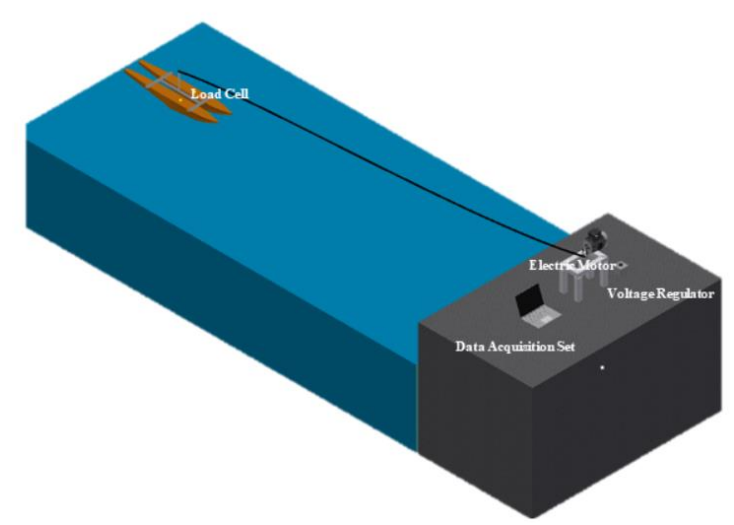

(a)

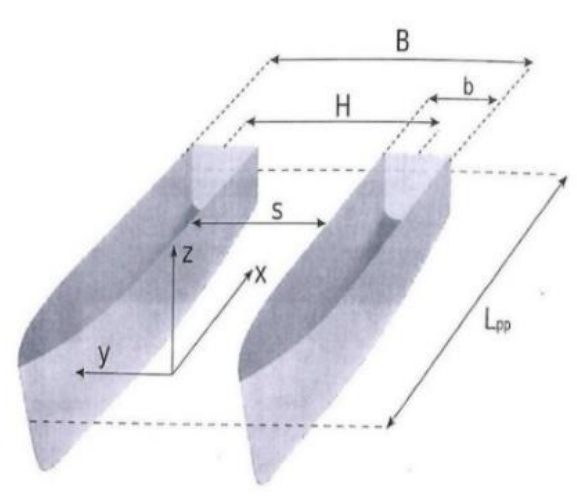

(b)

Figure 2 (a) Schematic drawing of the experimental setup; (b) Basic geometry definition of the catamaran model

Seif and Amini (2004) simplified the components of resistance in calm water by letting the tank sit for 30 minutes before the next experimental procedure took place. There are two things that have been the focus, namely viscous resistance and wave resistance. International standards from ITTC 7.5-01-01-01 classify hull ship resistance in calm water into two main components, namely viscous resistance associated with Reynolds numbers and wave-making resistance, which depends on the Froude number. Wave resistance $\left(R_{W}\right)$ contains the ideal fluid component (inviscid). Viscous resistance $\left(\mathrm{R}_{V}\right)$ includes resistance due to shear stress (friction drag) and viscous pressure components. This experiment used the total coefficient $\left(\mathrm{C}_{\mathrm{T}}\right)$ because it represents the ship's characteristics. Therefore, the experiment analyzed the final result by calculating the total resistance shown in Equation 1:

$$
C_{T}=\frac{R_{T}}{\frac{1}{2} \rho v^{2} S}
$$

Air resistance was ignored in this experiment. The notation of $S$ in Figure $2 \mathrm{~b}$ stands for the distance between the center line of the main hull and the other main hull. In this experiment, there were three variations of hull separation ratio $(S / L)$. Table 2 shows the hull separation ratio used in this experiment. The configuration of the hull separation ratio is based on the test results of a previous study by Yanuar et al. (2013). 
Table 2 Hull separation ratio used in this experiment

\begin{tabular}{cc}
\hline Configuration & $S / L$ \\
\hline A & 0.15 \\
B & 0.20 \\
C & 0.25 \\
\hline
\end{tabular}

\subsection{CFD Method}

Mathematically speaking, the equations governing the movement of fluids around ships have been known since time immemorial. With the sophistication of current technology, the Navier-Stokes equation has been solved using numerical algorithms used in predicting fluid motion (Guo et al., 2004). With the help of computers, fluid dynamics can be analyzed easily with a method called computational fluid analysis (CFA). Computerassisted fluid analysis is often used in predicting the water resistance of ships. According to Bustos and Alvarado (2017) real life scale of the test, the procedure was carried out with turbulent flow; therefore, this test was carried out using the RANS principle (Reynold Average Navier-Stokes). Shipping practitioners widely use this principle because other methods such as LES (Large Eddy Simulation) and DNS (Direct Numerical Solution) require a computer with high specifications (Ozdemir et al., 2014). The RANS (Reynold Average Navier-Stokes) equation can be seen in Equation 2:

$$
\frac{\partial k}{\partial t}+U_{j} \frac{\partial k}{\partial x_{j}}=P_{k}-\beta * k \omega+\frac{\partial}{\partial x_{j}}\left[\left(v+\sigma_{k} v_{T}\right) \frac{\partial k}{\partial x_{j}}\right]
$$

Turbulence is modeled by the k-Omega SST method, which uses Equation 3:

$$
\frac{\partial \omega}{\partial t}+U_{j} \frac{\partial \omega}{\partial x_{j}}=\alpha S^{2}-\beta \omega^{2}+\frac{}{\partial x_{j}}\left[\left(v+\sigma_{\omega} v_{T}\right) \frac{\partial \omega}{\partial x_{j}}\right]
$$

Then, the numerical method used a -three-step process: pre-processing, solving, and postprocessing.

\subsubsection{Pre-processing and solving}

In conducting CFD analysis, the first process is pre-processing. The ship geometry model is imported in the STL format, and then the mesh area is determined. The meshing process is the process of dividing the components to be analyzed into small or discrete elements. Before it, we created a domain in the form of a box around the pontoon with boundary standards following ITTC regulations with three setups: the inlet at 1-L of the ship model; the input performed in fixed velocity, which is the speed of the ship; and the outflow at 2-L behind the ship model with constant pressure. Lastly, the boundary is at a half clearance on the catamaran hull, provided that the overall length of the ship model and setting mesh convergence to be set in the number of cells to be 743.302 pieces with an error of $7.6 \%$. After this, the CFD pre-processing is carried out with time control for $5 \mathrm{~s}, \Delta \mathrm{t}$ of $0.001 \mathrm{~s}$, and run time of $0.25 \mathrm{~s}$.

\subsubsection{Post-processing}

The post-processing is done with the ParaView ${ }^{\mathrm{TM}}$ application included in the CFDSOF $^{\mathrm{TM}}$ v1.5 software. At this stage, the calculation results will be displayed by visualizing the fluid flow in the model. Numerical data are displayed in this stage by using quantitative calculations, where the data taken is in the form of pressure, density, total pressure, and wall shear. Some data that is displayed visually can be seen in Figure 3. The test was carried 
out by simulating the resistance of a model ship that was traveling on the water surface with Froude numbers 0.35 to 0.65 .

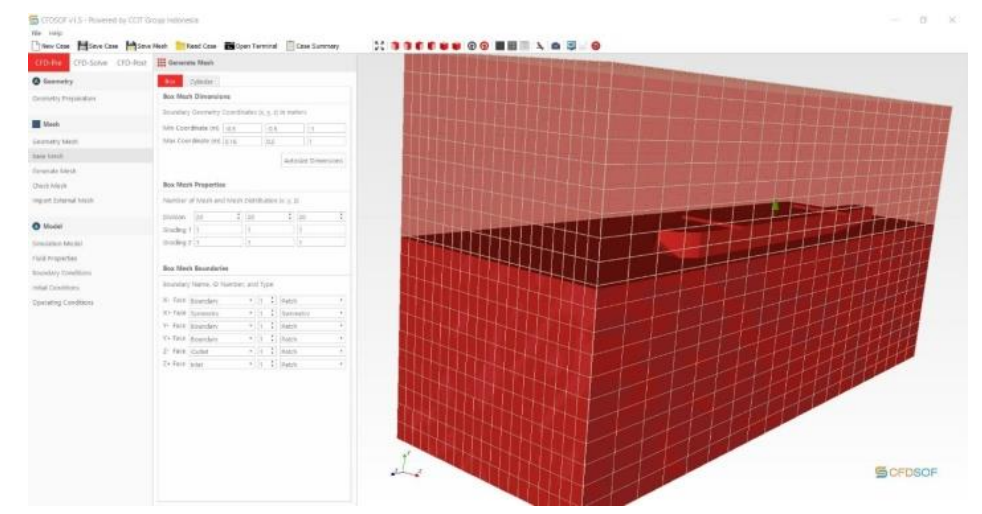

Figure 3 3D Model ships imported into CFDSOF software

\section{Results and Discussion}

After analyzing the total drag test, vessel resistance coefficient (CT) against Froude Number (Fr) in the clearance configuration of $0.15,0.2$, and 0.25 . We could conjure the graph of the total drag test vessel coefficient (CT) against Froude Number (Fr) on the clearance variation S/L. In testing the experimental method of the catamaran model ship pull test, the total ship resistance coefficient (CT) value is different for each clearance configuration. The graph in Figure 4 a states that the greater the clearance configuration, the smaller the ship's total drag coefficient (CT) value of the Froude Number (Fr) value. Meanwhile, the graph in Figure $4 \mathrm{~b}$ states that the greater the clearance configuration, the smaller the total ship resistance coefficient (CT) value for most of the Froude Number (Fr) values.

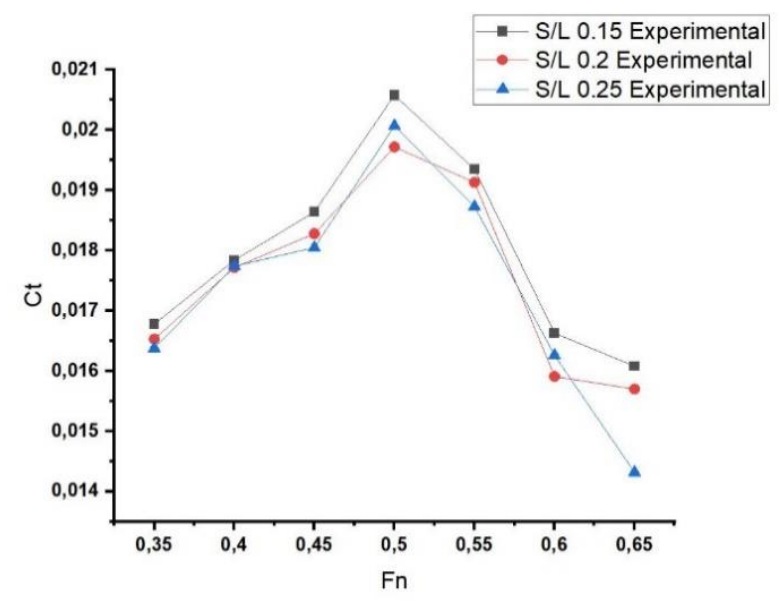

(a)

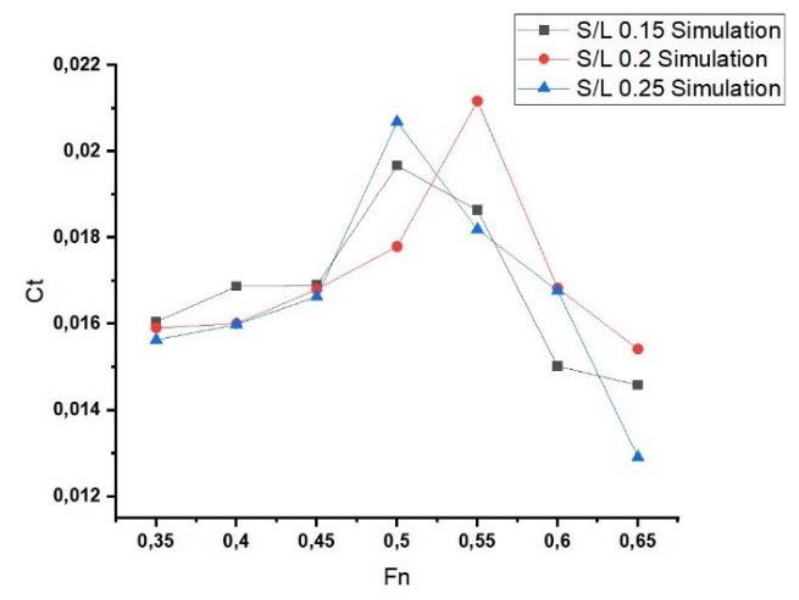

(b)

Figure 4 (a) Total resistance coefficient in experimental method; (b) Total resistance coefficient in CFD simulation method

In Figure $4 b$, it can be seen that the total resistance coefficient (Ct) to Froude Number has decreased, the same as in the experimental test shown in Figure 4a. The total resistance coefficient $(\mathrm{Ct})$ also decreased along with the increase in the variation in clearance distance (S/L) with a value of 0.008146 at S/L 0.25 with an Fn value of 0.75 . In Figures $4 \mathrm{a}$ and $4 \mathrm{~b}$, the results of processing data from experimental tests and numerical tests are shown when 
combined. It can be seen that the total resistance coefficient trend in numerical testing appears to have a smaller value than the experimental test. This occurs because of slight differences in the geometry of the physical model made with the software model, and the trim and sinkage factor is not taken into account in simulation testing. Another reason that it occurs is due to the large number of external factors when testing experiments carried out in the pond, such as the inconsistent wind and water surface conditions. It can be seen that the biggest error occurs in Froude Number (Fn) 0.40 in the clearance variation (S/L) 0.15 of $15.28 \%$ with a total resistance coefficient $(\mathrm{Ct})$ of 0.01337 in the experimental test and 0.01133 in the numerical test, while the smallest error occurs at Froude Number (Fn) 0.60 with a variation of clearance distance (S/L) 0.20 with a value of $2.54 \%$ with a total resistance coefficient $(\mathrm{Ct}$ ) of 0.01012 in the experimental test and 0.00986 in the numerical test.

The graph trend of the total drag coefficient $(\mathrm{Ct})$ from both tests experienced a sloping downward trend to Froude Number (Fn) 0.43, then experienced a steep decline afterwards. According to Souto-Iglesias et al. (2012) this occurs due to the interference factor of wave resistance, form resistance, and viscosity. The graph trend of the total drag coefficient (Ct) to the variation of the clearance distance (S/L) decreased along with the increase in clearance (S/L). It can be seen that the total resistance coefficient $(\mathrm{Ct})$ at Froude Number (Fn) 0.40 at the clearance distance (S/L) 0.15 is $0.01337,0.01348$ at the clearance (S/L) 2.0, and 0.01293 at the clearance distance (S/L) 0.25 in experimental testing; a similar trend occurred in numerical testing. This happens because the wave resistance increases along with the decreasing clearance (S/L) value, according to Zaghi et al. (2011) and Moraes et al. (2004). The results of this study indicate that the use of biomimicry design shows an increase in the clearance and total resistance generated compared to previous studies with differences in configuration and design. Previous research, namely that of Yanuar et al. (2019) used a pentamaran configuration to produce the same total resistance as in this study. Meanwhile, in this study, this has been achieved by designing a catamaran on a seaplane floating pontoon that uses the characteristics of sailfish as a consideration of its biomimetic design. Therefore, it can be said that the biomimetic float design is better than the pentamaran design of the previous research.

\section{Conclusions}

From the experimental testing and numerical testing and analysis carried out in this study, the following can be concluded: (1) Experimental testing of the floating pontoon configuration with the smallest total resistance coefficient $(\mathrm{Ct})$ occurs at clearance $(\mathrm{S} / \mathrm{L})$ 0.25 with Froude Number (Fn) 0.75 of 0.00681 , while the largest total drag coefficient (Ct) occurs at clearance (S/L) 0.15 with Froude Number (Fn) 0.40 with a value of $0.01337 ;(2)$ Numerical testing of the floating pontoon configuration with the smallest total drag coefficient (Ct) occurs at clearance (S/L) 0.25 with Froude Number (Fn) 0.75 of 0.00815 , while the largest total drag coefficient $(\mathrm{Ct})$ occurs at clearance $(\mathrm{S} / \mathrm{L}) 0.15$ with Froude Number (Fn) 0.40 with a value of 0.01133 ; (3) The results of numerical testing are carried out with validation with an error of $15.28 \%$ on the total resistance coefficient test compared to the experimental test results; (4) The biomimetics design is much preferable to that of a previous study done by Yanuar et al. (2019) because it uses a catamaran design rather than a pentamaran design to achieve the same total resistance at the same speed. 


\section{Acknowledgements}

This research is funded by Program Hibah PUTI Proceedings under contract number NKB-1098/UN2.RST/HKP.05.00/2020.

\section{References}

Bustos, D.S.H., Alvarado, R.J.P., 2017. Numerical Hull Resistance Calculation of a Catamarán using Openfoam. Ciencia y tecnología de buques, Volume 11(21), pp. 29-39

Danışman, D., 2014. Reduction of Demi-Hull Wave Interference Resistance in Fast Displacement Catamarans Utilizing an Optimized Centerbulb Concept. Ocean Engineering, Volume 91, pp. 227-234

Everest, J.T., 1968. Some Research on the Hydrodynamics of Catamarans and Multi-Hulled Vessels. In: North East Coast Institution of Engineers and Shipbuilders, N.n, Ulan Press, France, pp 1-20

Fish, F.E., Kocak, M.D., 2011. Biomimetics and Marine Technology: An Introduction. Marine Technology Society Journal, Volume 45(4), pp. 8-13

Gudmundsson, S., 2013. General Aviation Aircraft Design: Applied Methods and Procedures. $1^{\text {st }}$ Edition. London: Elsevier

Guo, B., Ghalambor, A., Duan, S., 2004. A Rigorous Approach to Estimating Permeability from Capillary Pressure Curves. Petroleum Science and Technology, Volume 22(3-4), pp. 319-335

Insel, M., Molland, A.F., 1992. An Investigation into the Resistance Components of HighSpeed Displacement Catamarans. Trans RINA, Volume 134, pp. 1-20

Iqbal, M., Samuel., 2017. Traditional Catamaran Hull Form Configurations that Reduce Total Resistance. International Journal of Technology, Volume 8(1), pp. 85-93

ITTC, 2011. Recommended Procedures and Guideline: 7.5-02 -02-01. Resistance Test. Rev 03

Moraes, H.B., Vasconcellos, J.M., Almeida, P.M., 2007. Multiple Criteria Optimization Applied to High-Speed Catamaran Preliminary Design. Ocean Engineering, Volume 34(1), pp. 133-147

Moraes, H., Vasconcellos, J., Latorre, R., 2004. Wave Resistance for High-Speed Catamarans. Ocean Engineering, Volume 31(17-18), pp. 2253-2282

Oving, A.J., 1985. Resistance Prediction Method for Semi Planing Catamarans with Symmetrical Demi-hulls. Master's Thesis, Graduate Program, Delft University of Technology, Mekelweg, Nedherland

Ozdemir, Y.H., Barlas, B., Yilmaz, T., Bayraktar, S., 2014. Numerical and Experimental Study of Turbulent Free Surface Flow for a Fast Ship Model. Brodogradnja, Volume 65(1), pp. $39-54$

Papanikolaou, A., 2005. Review of Advanced Marine Vehicles Concepts. In: Proceedings of the $7^{\text {th }}$ Symposium on High-Speed Marine Vehicles (HSMV), Napoli, Italy, 21-23 September 2005

Pien, P.C., 1976. Catamaran Hull-Form Design. In: International Seminar on Wave Resistance, Society of Naval Architects of Japan (SNAJ), pp. 14-25

Piscopo, V., Scamardella, A., 2015. The Overall Motion Sickness Incidence Applied to Catamarans. International Journal of Naval Architecture and Ocean Engineering, Volume 7(4), pp. 655-669

Pohlmann, D.L., 2016. Review: Biomimicry-Innovations Inspired by Nature by Janine M. Benyus US-NY William Morrow. INSIGHT, Volume 19(3), pp. 78-78 
Samuel., Iqbal, M., Utama, I.K.A.P., 2015. An Investigation into the Resistance Components of Converting a Traditional Monohull Fishing Vessel into Catamaran Form. International Journal of Technology, Volume 6(3), pp. 432-441

Sani, M.S.H.M., Muftah, F., Tan, C.S., 2013. Biomimicry Engineering: New Area of Transformation Inspired by the Nature. In: Business Engineering and Industrial Applications Colloquium (BEIAC), pp. 477-482

Seif, M.S., Amini, E., 2004. Performance Comparison between Planing Monohull and Catamaran at High Froude Numbers. Iranian Journal of Science \& Technology, Volume 28, pp. 435-441

Souto-Iglesias, A., Fernandez-Gutierrez, D., Pierez-Rojas, L., 2012. Experimental Assessment of Interference Resistance for a Series 60 Catamaran in Free and Fixed Trim-Sinkage Conditions. Ocean Engineering, Volume 53, pp. 38-47

Svendsen, M.B.S., Domenici, P., Marras, S., Krause, J., Boswell, K.M., Rodriguez-Pinto, I., Wilson, A.D.M., Kurvers, R.H.J.M., Viblanc, P.E., Finger, J.S., Steffensen, J.F., 2016. Maximum Swimming Speeds of Sailfish and Three Other Large Marine Predatory Fish Species based on Muscle Contraction Time and Stride Length: A Myth Revisited. Biology Open, Volume 5(10), pp. 1-18

Tomaszewski, K.M., 1950. Hydrodynamic Design of Seaplane Floats. Report Ministry of Supply, Aero Nautical Research Council, London, England

Yang, C., Lohner, R., Soto, O., 2002. Optimization of a Wave Cancellation Multihull Ship using CFD Tools. Journal of Hydrodynamics, Volume 14(1), pp. 1-8

Yanuar., Gunawan., Talahatu, M.A., Indrawati, R.T., Jamaluddin, A., 2013. Resistance Analysis of Unsymmetrical Trimaran Model with Outboard Side Hulls Configuration. Journal of Marine Science and Application, Volume 12(3), pp. 293-297

Yanuar., Ibaddurahman., 2019. An Investigation of the Pentamaran Resistance Characteristic with Variance in Hull Combination and Configuration. Energy Procedia, Volume 156, pp. 469-474

Yanuar., Ibadurrahman., Putri, S.A.A., 2019. Resistance Characteristics of Submerged Projectile with Bow Variation based on Hull Envelope Equation using Steady RANS Simulation. International Journal of Technology, Volume 10(4), pp. 677-688

Zaghi, S., Broglia, R., Di Mascio, A., 2011. Analysis of the Interference Effects for High-Speed Catamarans by Model Tests and Numerical Simulations. Ocean Engineering, Volume 38(17-18), pp. 2110-2122

Zouridakis, F., 2005. A Preliminary Design Tool for Resistance and Powering Prediction of Catamaran Vessels. Master's Thesis, Graduate Program, Massachusetts Institute of Technology, Cambridge, USA 